\title{
Machado de Assis como crítico de seu tempo
}

\author{
Machado de Assis as a Critic of his Time
}

\author{
Thiago Elias Ribeiro
}

\begin{abstract}
RESUMO
A partir do estudo de contos de Machado de Assis, especificamente, "Pai contra mãe" e "O caso da vara", temos por objetivo verificar como aparecem representadas literariamente relações sociais, morais e econômicas dentro dos contextos e situações observados. A partir dessas observações buscaremos a influência que isso terá nas atitudes e ações dos personagens dos contos analisados, e de que forma os personagens se encontram dentro desse contexto social. Não encerrando por aí as discussões, buscaremos as possibilidades e oportunidades que esses personagens teriam em optar por outros desfechos para suas histórias.
\end{abstract}

Palavras-chave: Machado de Assis; "O caso da vara"; "Pai contra mãe".

\begin{abstract}
From the study of Machado de Assis' tales, specifically, "Father vs. Mother" and "The Case of the Stick", we aim to verify how literary social, moral and economic relations appear within the observed contexts and situations. From these observations we will seek the influence that this will have on the attitudes and actions of the characters of the stories analyzed, and how the characters are within this social context. Not ending the discussions, we will seek the possibilities and opportunities that these characters would have in opting for other outcomes for their stories.
\end{abstract}

Keywords: Machado de Assis; "O caso da vara"; "Pai contra mãe".

\footnotetext{
* Departamento de Línguas e Letras - Universidade Federal do Espírito Santo - UFES - 29075910 - Vitória - ES - Brasil. E-mail: thiagoer@yahoo.com.br.
} 


\section{INTRODUÇÃO}

Machado de Assis estava radicalmente atento às questões de seu tempo, entre elas, a escravidão. Em sua obra, elaborava uma reflexão profunda da sociedade, denunciando suas mazelas, mas sem apontar a culpa para indivíduos específicos, uma vez que estes representavam, na ficção, costumes, valores, ideias e instituições.

"Pai contra mãe", doravante PMC e "O caso da vara", doravante CV, demonstram embates e problemas a que estão submetidos os indivíduos que se encontram em situação marginal. Machado aborda as relações conflituosas, as relações de poder, a extrema desigualdade, a luta de personagens marginais em busca da sobrevivência. Em PCM e CV, a crítica se dirige, sem rebuços, à existência da escravidão. É relevante registrar que a ação das narrativas remonta à época do auge da escravidão, anterior às tentativas de libertação, apesar de terem sido escritas após à abolição da escravatura, deixando evidente, que, mesmo depois de 1888, a escravidão deixou suas marcas de crueldade e desumanidade.

Para alguns críticos de Machado de Assis, como Silvio Romero, Araripe Júnior e José Veríssimo, à obra machadiana faltava engajamento político, sentimento nacional e cor local. A nossa posição - como a de praticamente toda a crítica de alguns bons anos para cá - é radicalmente outra.

\section{Análise e interpretação de "Pai contra mãe"}

PCM, Escrito em 1906 e publicado na coletânea Relíquias da casa velha, é uma reflexão em torno de uma sociedade patriarcal, escravista e com pouca ou nenhuma mobilidade social para os membros das camadas inferiores. No conto, o narrador se apropria do discurso dominante e, com singular ironia, descreve aspectos e aparelhos da escravidão como forma de manutenção da "ordem social e humana". Na citação desses instrumentos, há a menção da "máscara de fôlha-de-flandres" - obra de funilaria com apenas dois buracos para ver e um para respirar - que era utilizada para o escravo "perder o vício da embriaguez". E segue com o comentário de que tais instrumentos eram cruéis, 
mas úteis para a manutenção da ordem social, pois "essa nem sempre se alcança sem o grotesco e alguma vez o cruel.” (MACHADO DE ASSIS, DATA, p. 9)

O narrador começa o conto descrevendo alguns aspectos da escravidão na época, a dominação imposta sobre os escravos, as tentativas de naturalização da barbárie e as justificativas para a existência de tal situação desumanizadora. Ao refletir sobre essa descrição, Octavio Ianni (1988), aponta com clareza para a preocupação de Machado de Assis com a questão do negro, contribuindo para desfazer as acusações de que o Bruxo do Cosme Velho era alheio a essas questões. O crítico também chama a atenção para a subjetividade, a sensibilidade e a perspicácia na narração que aparenta ser naturalista, fria, uma aula de "mecânica", mas se revela "enxuta, contida e tensa." (IANNI, 1988, p.94)

Outro ponto fundamental é a apresentação do "ofício do tempo", que era pegar escravos. Uma profissão em que podiam se encaixar as pessoas que não conseguiam alcançar o seu sustento por meio de empregos tradicionais. Nesse contexto surge Cândido Neves, chamado de Candinho em família, sujeito e sujeitado desse modelo social. Não era negro, nem escravo, mas nem por isso era menos excluído.

A falta de persistência em empregos que resultavam em pequenos salários e algum tipo de submissão que "feria-o na corda do orgulho" (MACHADO DE ASSIS, 1962, p.12), Levaram Cândido a “ceder à pobreza quando adquiriu o ofício de pegar escravos" (MACHADO DE ASSIS, 1962, p.11).

A visão aqui utilizada será a observação social e moral sobre a atitude final desse personagem de entregar a escrava ao proprietário, a qual foi tomada diante de uma situação-limite em que ele mesmo não tinha sustento para o próprio filho.

A começar por Cândido, sua esposa, Clara, e a tia dela, Mônica, todos se encontravam em uma condição econômico-social desfavorável, justamente por pertencerem a uma classe marginal. Sobre essa relação, Roberto Schwarz escreve:

Não sendo proprietários nem escravos, estas personagens não formam elementos básicos da sociedade, que lhes prepara para uma situação ideológica desconcertante. O seu acesso aos bens da civilização, dada a dimensão marginal do trabalho livre, se efetiva somente através da 
benevolência eventual e discricionária de indivíduos da classe abonada. (UMPC, Schwartz, p.83).

Não pertencendo a nenhuma das classes de maior poder financeiro, como os grandes comerciantes, fazendeiros e proprietários de escravos, restou ao protagonista da história servir à dominação por meio da captura de escravos fugidos em troca de recompensas. Vivia assim, e sustentava sua família com a infelicidade de quem era devolvido e com o dinheiro que lhe davam pelo serviço, visto que a sociedade e a economia da época eram mantidas basicamente por esse sistema escravista.

Porém essa situação não se sustenta para sempre, os escravos começam a faltar e as recompensas também, aumenta o número de desempregados e a procura por essa função, que afinal "era um oficio do tempo" (MACHADO DE ASSIS, 1962, p.11). Tudo isso como reflexo da marginalidade e da necessidade a que estavam expostos esses indivíduos, como afirma o conto: "Ninguém se metia em tal ofício por desfastio ou estudo; a pobreza, a necessidade de uma achega, a inaptidão para outros trabalhos, o acaso [...]" (MACHADO DE ASSIS, 1962, p. 11).

A crise agrava-se e começa a faltar recurso para o sustento da família, o que é aumentado com a expectativa da chegada do primeiro filho. Pouco antes do nascimento do bebê e com o despejo da família, tia Mônica cogita a possibilidade da entrega do filho à Roda dos enjeitados, local em que as crianças pobres eram deixadas para ser criadas por religiosas. Esta sugestão é rechaçada pelos pais do menino até o momento em que se veem morando de favor e sem nenhuma condição de sustentar o filho.

A única opção possível e imediata seria encontrar uma escrava fugida de nome Arminda cuja recompensa pela captura "subia a cem - mil réis" (MACHADO DE ASSIS, 1962, p.21). Exacerba-se assim a relação de sobrevivência, que se torna possível apenas para um dos dois, como afirma Bosi: O bem estar de uns parece fundar-se na desgraça de outros. $\mathrm{O}$ acesso aos bens vitais e econômicos, por baixo que seja em termos quantitativos (afinal, Candinho é pobre), exige a espoliação do outro. A lei é sempre: mors tua vita mea. (M. de A.,Bosi, p.456).

Ao conhecer a condição social de cada um dos envolvidos, não é preciso muito esforço para perceber que com o encontro de Cândido e Arminda, o primeiro se 
beneficiará, não somente pela força física, mas também pela estrutural (social e econômica). A má condição financeira não apaga o fato de Cândido ser homem, branco e, de certo modo, livre (não escravo).

O reconhecimento por parte da escrava da sua total falta de direito também se dá: "A escrava quis gritar, parece que chegou a soltar alguma voz mais alta que de costume, mas entendeu logo que ninguém viria libertá-la, ao contrário. (p. 24). Restava uma única opção cabível para ela, que era pedir e implorar: "Pediu então que a soltasse pelo amor de Deus" (MACHADO DE ASSIS, 1962, p. 24).

A captura, a entrega da escrava e o recebimento da recompensa livraram Cândido de entregar o próprio filho à Roda dos enjeitados, porém a violência com que tal ação foi conduzida fez com que Arminda abortasse. Segundo Rosália Diogo, a cena da captura da escrava mostra, com contundência, a crítica realizada por Machado ao sistema escravista. E segue afirmando que ao optar por descrever o desenlace de forma bastante violenta utilizando verbos como "gemer", "arrastar", “castigar", "açoitar" - Machado de Assis faz com que fique evidente a violência presente na captura.

A ausência de direitos de Arminda como mulher e escrava, era reconhecida por todos, pois "quem passava ou estava à porta de uma loja, compreendia o que era e naturalmente não acudia." (MACHADO DE ASSIS, 1962, p.24 - grifo nosso) Além disso, ainda há acusação de Candido ao ponderar que a culpa do desfecho trágico, é da própria Arminda. A acusação feita, pelo caçador de escravos, revela ser um reflexo da mentalidade de boa parte da sociedade sobre a mulher, sobretudo sendo ela escrava. $\mathrm{O}$ caçador de escravos diz: "Você é que tem culpa. Quem lhe manda fazer filhos e depois fugir?" (p.25)

E, como se não bastasse, o conto se encerra com mais uma frase de Candido que tenta naturalizar a crueldade ou justificar as suas ações e acalmar a própria consciência ao dizer que "nem todas as crianças vingam". (MACHADO DE ASSIS, 1962, p. 26)

Diante dessa reflexão é possível perceber que as relações sociais impõem aos indivíduos marginais ações desesperadas que não podem ser julgadas com uma acusação pura e simples, sem mediações. Não se trata de justificar ou perdoar as ações de Candinho 
- mas de entendê-las à luz do contexto social. Essas atitudes denunciam o modo opressor, a um tempo sutil e explícito, com que a sociedade obriga os sujeitos excluídos a cometerem ações que atentam contra a dignidade de outros sujeitos ainda mais excluídos. Uma espécie de conflito entre o roto e o ainda mais esfarrapado. Sobre isso, comenta Bosi:

\begin{abstract}
A necessidade de vencer na vida - mola universal - só é satisfeita pela união ostensiva do sujeito com a Aparência dominante. E por acaso, será ilícito culpar esse pobre e vulnerável sujeito porque subiu a maré de seu tempo para não afogar-se na pobreza, na obscuridade e na humilhação? [...] (Bosi et. Al., 1982, p. 86).
\end{abstract}

Machado busca com isso apontar para um gravíssimo problema social que se desenvolveu ao longo de séculos e que se perpetua até os dias de hoje. A existência de pessoas exploradas, de pessoas miseráveis, de pessoas escravizadas, e outras pessoas abastadas, pessoas poderosas, que exploram aquelas. Essa desigualdade se caracteriza como a mola mestra que faz girar essa sociedade, que possui necessidade dessa estrutura para sustentar a ordem vigente. Há uma dificuldade imensa em se romper tal estrutura, nos diz Machado em sua obra.

\title{
Análise e interpretação de "O caso da vara"
}

Também em “O caso da vara” (1891) está presente a difícil situação que envolve, de um lado, um membro não de pequeno poder aquisitivo, mas com dependência acentuada de um membro detentor de autoridade. E, do outro um pai oligarca e detentor de todas as vontades dos que o cercam e dele dependem financeiramente.

Em "O caso da vara", a predominância da vontade do pai em querer enviar o filho, Damião a um seminário para padres mostra a configuração dessa sociedade em que um sujeito que está no topo das relações de poder, impõe aos outros que estão em um nível inferior as suas próprias posições, não admitindo receber recusas nem questionamentos.

A figura do pai, apesar de pouco presente explicitamente no texto, é de vital importância pela posição que ele ocupa na história: o lugar de primeiro algoz nesse 
sistema oligárquico, patriarcal e dominador. Primeiro, porque ao término do conto seu filho parece ocupar, então, a posição de opressor da cria de Sinhá Rita. Se não de opressor, pelo menos de conivente, visto que ele, talvez, não pudesse fazer nada para ajudar a menina. Entretanto, ele também nem se pronuncia.

De volta ao pai, ele é responsável por todo o ocorrido, pois é por causa da vontade dele em fazer o filho padre que acontece toda a situação presenciada na história. Ele não tem um nome, talvez por não representar uma pessoa e sim uma posição social. Ele é tido como intransigente por todos; pelo filho "Para aonde iria? Para casa não; lá estava o pai que o devolveria ao seminário, depois de um bom castigo.” (MACHADO DE ASSIS, 1955, p. 11); por Sinhá Rita “... e então seu pai, que dizem que é zangado.” (MACHADO DE ASSIS, 1955, p.13); por João Carneiro “... conhecia o velho; era capaz de lhe quebrar uma jarra na cara.” (MACHADO DE ASSIS, 1955, p.17)

À medida que um membro de uma condição econômica inferior tenta romper com a estrutura social presente, inicia-se aí um dos conflitos do conto. Por causa dessa situação de dominação e opressão, em cadeia, surge de um lado Damião. E do outro Lucrécia “[...] uma negrinha, magricela, um frangalho de nada, com uma cicatriz na testa e uma queimadura na mão esquerda" (MACHADO DE ASSIS, 1955, p. 15).

Quando se vê diante da possibilidade de sofrer as consequências da não obediência a seu pai, Damião pensa em buscar ajuda de alguém que possa fazer frente à vontade e à autoridade paterna. Depois de muito pensar, lhe vem à cabeça o padrinho, João Carneiro, que é excluído de pronto, pois ele o concebe como “...um moleirão sem vontade, que por si só não faria coisa útil.” (MACHADO DE ASSIS, 1955, p.41).

Damião vê uma possibilidade ao lembrar-se de Sinhá Rita que era uma viúva conhecida da família e "querida de João Carneiro" (MACHADO DE ASSIS, 1955, p.12). O narrador aponta as causas por que o menino busca essa senhora para lhe ajudar e, com isso, mostra as contradições dessa sociedade, pois Sinhá Rita era viúva e mantenedora de uma estranha relação que lhe dá uma forte autoridade sobre João Carneiro.

É possível notar que existia um caso entre Sinhá Rita e João carneiro, tido como natural por eles e talvez por outros membros da sociedade conhecedora daquela situação 
que, no entanto, parece ser aceito, ainda que com um pouco de disfarce. Apesar de partes no texto que dão certeza sobre a relação ilícita: "Sinhá Rita dispunha justamente de um rodaque $^{1}$, lembrança ou esquecimento de João Carneiro.” (MACHADO DE ASSIS, 1955, p.20).

Sinhá Rita é caracterizada pelo narrador como uma pessoa "apessoada, viva, patusca, amiga de rir; mas quando convinha, brava como o diabo." (MACHADO DE ASSIS, 1955, p.15) A autoridade que exercia sobre o "amigo do marido" (MACHADO DE ASSIS, 1955, p.15), é apontada por diversas vezes pelo narrador como em: "Chamou um moleque e bradou-lhe que fosse à casa do Sr. João carneiro chamá-lo, já e já; e se não estivesse em casa, perguntasse onde podia ser encontrado, e corresse a dizer-lhe que precisava muito lhe falar imediatamente.” (MACHADO DE ASSIS, 1955, p.14).

Percebe-se que, diante do menino, ela chama João Carneiro de "Senhor", mas apenas como tentativa de encobrir o mando, sendo que o narrador expõe a justificativa dando realce para os leitores da verdadeira autoridade dela: "Ela, para mascarar a autoridade com que dera aquelas ordens, explicou ao moço que Sr. João Carneiro fôra amigo do meu marido e arranjara-lhe algumas crias para ensinar." (MACHADO DE ASSIS, 1955, p.15).

Também em outras partes do texto pode-se ver essa relação de domínio. A certa altura, o padrinho chega e promete castigar o menino e ela diz: "- qual castigar que nada! Interrompeu Sinhá Rita. Castigar por quê? Vá, vá falar a seu compadre.” (MACHADO DE ASSIS, 1955, p.16) Ou na parte em que ela com ameaça, escreve: "Joãozinho, ou você salva o moço, ou nunca mais nos vemos".

Também esse senhorio, exercido por Sinhá Rita, era conhecido do padrinho de Damião, o que é demonstrado quando ela diz para ele falar com o compadre: "e, se fôsse negativo, outra luta com Sinhá Rita, cuja última palavra era ameaçadora: 'digo-lhe êle não volta'.” (MACHADO DE ASSIS, 1955, p. 17).

\footnotetext{
${ }^{1}$ Rodaque: Casaco masculino, espécie de sobrecasaca.
} 
O menino, para tentar fugir ao destino escolhido pelo pai; acaba ficando à mercê da ajuda de Sinhá Rita, pois se vê dependente do favor dela, e acaba se colocando na posição de opressor na relação com a menina, quando essa não conclui suas tarefas; uma vez que não se posiciona contra o algoz de Lucrécia e até mesmo lhe entrega o objeto de castigo, a vara.

Com isso, percebe-se novamente um embate em que somente um sairá beneficiado. E, mais uma vez é a possível escrava, já que o texto não diz a real condição dela naquela sociedade, a quem caberá o lado mais negativo. Afinal, "a corda sempre arrebenta no lado mais fraco", diz o jargão popular.

O narrador aponta ainda o fato de que Lucrécia "tossia, mas para dentro, surdamente, a fim de não interromper a conversação." (MACHADO DE ASSIS, 1955, p. 16). O que leva à interpretação de que ela pudesse ter alguma doença não tratada e desconsiderada pelos demais, pelo fato de ser ela esse membro não importante dessa sociedade. Entretanto não se pode deixar de considerar que a ajuda de Sinhá Rita era, talvez, o único meio de que Damião dispunha para conseguir seus intentos.

\section{Considerações finais}

Machado de Assis mostra que todos os que estão na base da pirâmide social, como aponta Raimundo Faoro, no livro Machado de Assis: a pirâmide e o trapézio (1974), são assujeitados e colocados à margem da sociedade por aqueles poucos que estão no topo. E que, nessa sociedade de luta de classes sempre haverá a quem caiba um pouco mais de opressão para que outros possam sobreviver.

Machado demonstra, com a crueza irônica que a situação produz, que nessa sociedade de exclusão ainda há vias de escape para as pessoas que são relativamente livres, mas para os escravos que nem eram considerados como pessoas, não. Portanto toca nessa ferida aberta da sociedade da época, demonstrando ainda mais sua miséria e nos

fazendo ver que a catástrofe de outrora ganhou formas novas e mais sutis na contemporaneidade. 


\section{REFERÊNCIAS}

MACHADO DE ASSIS, J. M. Pai contra mãe. In: Relíquias de casa velha. São Paulo: W.M. Jackson, 1962. p. 9-26.

O caso da vara. In: Páginas Recolhidas. São Paulo: W.M. Jackson, 1955. p. 11- 23.

BOSI, A. et. al. Machado de Assis. São Paulo: Ática, 1982. [col. Escritores brasileiros - Antologia e estudos].

DIOGO, R. A escrita machadiana e a literatura negra. Cadernos CESPUC de pesquisa, Belo Horizonte, s./v., n. 18, p. 145-153, 2009. Disponível em: http://periodicos.pucminas.br/index.php/cadernoscespuc/article/view/2439. Acesso em: 21/07/2020.

DUARTE, E. A. Machado de Assis afro-descendente: escritos de caramujo. Rio de Janeiro; Belo Horizonte: Palas; Crisálida, 2007.

FAORO, R. Machado de Assis: a pirâmide e o trapézio. São Paulo: Brasiliana, 1974.

FANTINI, M. Machado de Assis. In. DUARTE, E. A. Literatura e afrodescendência no Brasil: Antologia crítica. Belo Horizonte: Editora UFMG, 2011. p. 143-171.

IANNI, O. Literatura e consciência. Revista do Instituto de Estudos Brasileiros, São Paulo, n. 28, p. 91-99, 1988 . Disponível em: http://www.revistas.usp.br/rieb/article/view/70034/72674. Acesso em: 21/07/2020.

PROENÇA FILHO, D. A trajetória do negro na literatura brasileira. Estudos Avançados, s. v., n. 18, v. 50, p. 161-93,2004. Disponível em: http://www.revistas.usp.br/eav/article/view/9980/11552. Acesso em: 21/07/2020. 
SCHWARZ, R. Um mestre na periferia do capitalismo: Machado de Assis. São Paulo: Duas Cidades; Ed. 34, 1997.

Ao vencedor as batatas. São Paulo: Duas Cidades; Ed. 34, 2000.

VELLINHO, M. Machado de Assis: "Histórias mal contadas" e outros assuntos. Rio de Janeiro: São José, 1960.

VILAÇA, A. Querer, poder, precisar: "O caso da vara". Teresa: Revista de Literatura Brasileira, São Paulo, n. 6, p. 18-30,2004. Disponível em: https://www.revistas.usp.br/teresa/article/view/116606/114194. Acesso em: 21/07/2020.

VITAL, S. Quase brancos, quase pretos: representação étnico-racial no conto machadiano. São Paulo: Intermeios, 2012.

Recebido em: 05/11/2021

Aprovado em: 02/12/2021

Publicado em: 08/12/2021 